\title{
LA REFORMA DEL ARTÍCULO 135 DE LA CONSTITUCIÓN ESPAÑOLA: ¿PUEDEN LOS MERCADOS QUEBRAR EL CONSENSO CONSTITUCIONAL? ${ }^{1}$
}

\author{
M JOSEFA RIDAURA MARTÍNEZ \\ Profesora Titular de Derecho Constitucional \\ Universitat de Valencia
}

SUMARIO
I. Introducción.
II. El Principio de estabilidad presupuestaria.
III. El Controvertido Procedimiento de Reforma.

\section{INTRODUCCIÓN}

El día 27 de septiembre de 2011 ha entrado en vigor la reforma del artículo 135 de la Constitución española de 1978, que extiende sustancialmente el contenido de dicho precepto; consagrando, como principio constitucional, el principio de estabilidad presupuestaria de las Administraciones; elevando el rango de un principio hasta ahora regulado tanto en el Derecho Comunitario como en nuestro ordenamiento orgánico y ordinario. Dándose lugar a una reforma del precepto constitucional, que a diferencia de la llevada a cabo en 1992, supone una reformulación del mismo, incorporando materias no reguladas previamente en dicho artículo.

El principio incorporado al texto constitucional constituye un principio clásico de la Ciencia de la Hacienda, aunque no exento de controversia ${ }^{2}$; habiendo sido defendido desde finales del Siglo XVIII por los economistas liberales. No obstante, en términos generales, no llegó a aplicarse en los Presupuestos, ni a concretarse jurídicamente como principio presupuestario ${ }^{3}$. Se trata, pues, de un principio con marcado perfil ideológico,

1 Este artículo se enmarca en el Proyecto de Investigación Ref. CSO2009-14381-C03-03, Financiado por el Plan Nacional de Investigación Científica, Desarrollo e Innovación Tecnológica 2010-2012.

2 DOMINGUEZ MARTINEZ, J.M. y LÓPEZ JIMENEZ, J.M.: «Estabilidad presupuestaria y reforma constitucional en España», Diario La Ley núm. 7760/2011, pág. 1.

3 Vid. MARTÍN QUERALT, J.; LOZANO SERRANO, C.; TEJERIZO LOPEZ, J.M.; CASADO OLLERO, G.: Curso de Derecho Financiero y Tributario, Tecnos, Madrid, 2011, págs. 740-741. 
ligado al liberalismo económico que postula el abstencionismo estatal frente a una mayor libertad de mercado, materializado constitucionalmente en el Estado liberal de Derecho; y contrapuesto a las tesis propias del intervencionismo propio del Estado social, que defienden la inversión pública y la intervención estatal en los ciclos de la economía, aun a pesar de la generación de déficit público (teoría Keynesiana) ${ }^{4}$.

El resurgimiento con fuerza en las últimas décadas de una nueva corriente de pensamiento liberal, identificada como neoliberalismo ${ }^{5}$, no ha estado exento de influencia en el proceso europeo configurador de una Unión Económica y Monetaria; que hace del principio de estabilidad presupuestaria el eje fundamental de la política económica comunitaria en materia presupuestaria; materializándose en el artículo 104 del Tratado de la Unión Europea, en el que se encomendaba a los Estados miembros que evitaran déficits públicos excesivos. Voluntad de estabilidad presupuestaria en el marco comunitario que se ve fortalecida con la aprobación en Amsterdam en el año 1997 del Pacto Europeo de Estabilidad y Crecimiento (PEC) ${ }^{6}$; y hoy día reconocida en el artículo 126 del Tratado de Funcionamiento de la Unión Europea, y reforzada en la reciente reformulación del PEC por el Parlamento Europeo.

La recepción en nuestro ordenamiento positivo del Derecho comunitario se materializó en la Ley 18/2001, de 12 de diciembre, General de Estabilidad Presupuestaria, modificada por el Real Decreto Legislativo 2/2007, de 28 de diciembre, que aprueba el texto refundido de la Ley General de Estabilidad Presupuestaria, complementado por la Ley Orgánica 5/2001, de 13 de diciembre, sobre las que posteriormente nos detendremos.

Este escenario normativo ha sido superado por la realidad de los hechos ante la gravedad, sin precedentes, de la crisis económica de finales de la década anterior; frente a la cual las exigencias jurídicas de estabilidad presupuestaria no han sido suficientes para embridar, tanto la radical caída de recaudación de ingresos públicos, como el necesario incremento de los gastos sociales, agravado por la crisis de la deuda soberana, de la que se ha hecho un uso abusivo para afrontar los crecientes déficits públicos.

En este marco de desconcierto económico generalizado en el ámbito de la zona euro, con riesgo inminente de intervención en países de importancia económica en el seno de la Unión, y ante el manifiesto fracaso de los mecanismos jurídico-institucionales de gobernanza europea, el eje franco-alemán toma, por la vía del peso de sus economías, el timón de la gobernanza europea; y en la reunión, celebrada en el Elíseo el día 16 de agosto de 2011, el presidente francés, Nicolás Sarkozy, y la canciller alemana, Angela Merkel, acordaron proponer al resto de miembros de la eurozona la adopción de una serie de medidas para reforzar la gobernanza económica de la eurozona y la austeridad fiscal. Siendo una de las más relevantes la inclusión en sus respectivas

4 Un estudio minucioso de las distintas corrientes puede verse en GARRORENA MORALES, A.: El Estado español como Estado Social y Democrático de Derecho, Tecnos, Madrid, 1984, así como en CARMONA CUENCA, E.: El Estado Social de Derecho en la Constitución, CES, Madrid, 2000.

5 Un estudio mas completo sobre este proceso puede verse en AGUIAR DE LUQUE, L. y ROSADO IGLESIAS, G.: «La estabilidad presupuestaria y su eventual proyección en el Estado de las Autonomías», Cuadernos de Derecho Público, núm. 12/2001, págs. 9 y ss.

6 Resolución del Consejo Europeo de 17 de junio de 1997, núm. 1466/1997, del Consejo, de 7 de julio, relativo al reforzamiento de la supervisión de las situaciones presupuestarias y a la supervisión y coordinación de las políticas económicas. [Diario Oficial C 236 de 2.8.1997]. Modificado por Reglamento (CE) $\mathrm{n}^{\circ}$ 1055/2005 del Consejo de 27 de junio de 2005 [DO L 174, 1 7.7.2005] 
Constituciones de una regla de equilibrio presupuestario: la denominada regla de oro, cuyo objeto es frenar el endeudamiento de los Estados miembros.

Esta previsión constitucional ya está contemplada en la Constitución alemana, que inspirada, a su vez, en la reforma de la Constitución Suiza del año 2001 (cuyo artículo 126 regula el freno al endeudamiento), reformó su texto en 2009 para introducir en los artículos 109. 3 y 115 el freno al endeudamiento aplicable tanto a la Federación como a los Länder; limitando al 0,35\% del PIB el déficit del Gobierno federal en el año 2015, y prohibiéndolo para los Länder a partir del año 20197. Sin embargo, se contemplan excepciones en caso de graves catástrofes naturales o situaciones de emergencia en las que podría votarse en el Parlamento un levantamiento del techo de deuda que sería compensado con un plan de amortización. Además, se crea un nuevo órgano que tiene como misión supervisar el nuevo sistema: el Consejo de Estabilidad (Stabilitätsrat) ${ }^{8}$.

Dicha reforma de la Ley Fundamental no causa extrañeza, habida cuenta de que Alemania fue la impulsora del Pacto Europeo de Estabilidad. Ahora bien, debe señalarse que la inclusión de dichas medidas en la Ley Fundamental de Bonn ha sido fruto de un proceso reflexivo, que contó con amplia participación de representantes de los órganos constitucionales, de los Länder y de las agrupaciones locales, así como de expertos en la materia. Proceso, que como veremos en este trabajo, contrasta con el que se ha llevado a cabo en España para reformar el artículo 135 de la Constitución.

En sintonía con el texto alemán, la «orden» proveniente de los líderes europeos de aplicar la «regla de oro» mediante la reforma constitucional vincula a cada Estado de la eurozona para que antes de que concluya el verano de 2012 sus Constituciones fijen el calendario del déficit cero. La recepción de este mandato en los países afectados no ha sido pacífica, sino que ha provocado una reacción adversa, ya que algunos de ellos se han opuesto de inmediato a la reforma de sus textos constitucionales para la implantación de dicha medida, apartándose así del modelo de la Ley Fundamental de Bonn. Las dificultades de implementación derivan de la oposición tanto de los responsables políticos, como de los grupos de la oposición cuyo apoyo resulta necesario para la aprobación de las reformas constitucionales; en este último caso cabe resaltar la dificultad del Presidente

7 Vid. el estudio de ARROYO GIL, A.: La Reforma constitucional del federalismo alemán, Un estudio crítico de la 52. 'Ley de modificación de la Ley Fundamental de Bonn, de 28 de agosto de 2006, Institut d' Estudis Autonomics, Barcelona, 2009, págs. 126 y ss; ELIAS DIAZ C.: «La reforma de la constitución financiera en Alemania: una reforma pendiente», ReDCE, núm. 6/2006; trabajos en los que se analiza el proceso de reforma de la Ley Fundamental en este tema. En concreto, expone Arroyo Gil que después de haber quedado pendiente la denominada Constitución financiera tras la reforma operada en la Ley Fundamental de 2006,» se aprobó por la Dieta Federal y el Consejo la constitución de Comisión para la modernización de las relaciones financieras entre la Federación y los Lander (Comisión sobre el federalismo II ), que estaba integrada por dieciséis miembros de cada uno de estos órganos constitucionales, en la que, además, también estaban presentes cuatro representantes de las Dietas de los Lander, sin derecho a voto, así como, por parte de las ciudades y municipios, tres representantes de las principales agrupaciones o asociaciones locales», de entre cuyos objetivos principales estaba «el establecimiento de establecer un limite efectivo al endeudamiento del Estado, con el objeto de evitar endeudamientos ilimitados»; «de conformidad con ese acuerdo alcanzado en el seno de la Comisión sobre el Federalismo II» se introdujo en la Constitución, (arts. 109 y 115 GG) un limite a la capacidad de endeudamiento de la Federación y los Lander. pág.126.

8 Vid. el reciente y exhaustivo estudio sobre la reforma constitucional alemana de EKKEHART REIMER; «La crisis financiera como oportunidad político-constitucional. El nuevo freno al endeudamiento en la Constitución alemana», Teoría y Realidad Constitucional, núm. 28/2011, págs. 93-132. 
francés (uno de sus impulsores) para aunar la mayoría requerida para la reforma constitucional, dada la oposición de los socialistas franceses; también en Portugal el presidente de la República ha manifestado desde el principio su negativa, tanto a reformar la Constitución, como a aplicar la limitación del déficit.

Sin embargo, a diferencia de otros países de nuestro entorno, 10 días después del anuncio efectuado por los dos líderes europeos, el 26 de agosto, los grupos parlamentarios Socialista y Popular presentaban ante la Mesa del Congreso la Proposición de Reforma Constitucional del artículo 135 de la Constitución con el objeto de garantizar el principio de la estabilidad presupuestaria, limitando el déficit de las administraciones públicas $^{9}$, y el día 27 de septiembre, una vez aprobada por las Cortes españolas, la reforma ha entrado en vigor. A día de hoy, tan sólo el texto constitucional español se ha reformado en cumplimiento del «mandato» europeo ${ }^{10}$.

Nos encontramos ante la segunda reforma del texto constitucional español desde que entró en vigor en el año 1978. La primera reforma se produjo por exigencia de la ratificación del Tratado de Maastricht, ya que, de acuerdo con el artículo 95.1 de la Constitución, la celebración de un Tratado que contenga estipulaciones contrarias a la misma exigirá la previa revisión constitucional. En virtud de esta cláusula, el Tribunal Constitucional entendió en su Declaración 1/1991, de 1 de julio de 1992 que la ratificación del Tratado exigía la reforma del artículo 13.2 de la Constitución. La reforma consistente en incluir en dicho precepto el derecho del sufragio pasivo de los extranjeros en las elecciones municipales ${ }^{11}$ se llevó a cabo a través del procedimiento ordinario de reforma, por el procedimiento de lectura única y no se sometió a referéndum, pero contó con el respaldo mayoritario de los grupos políticos con representación parlamentaria.

La segunda reforma es la del artículo 135 de la Constitución, objeto de análisis en este trabajo, que se promueve también como resultado de exigencias marcadas por la Unión Europea y, especialmente, de los mercados a quienes en el fondo se pretende tranquilizar con esta medida. La reforma del artículo 135 de la Constitución igualmente tiene su anclaje jurídico en el mismo Tratado de la Unión Europea ${ }^{12}$ (hoy TFUE), que, como hemos visto, erige al principio de estabilidad presupuestaria como un elemento esencial de la política económica comunitaria en materia presupuestaria.

Ciertamente, ni el contenido, ni el alcance de las dos reformas de la Constitución española de 1978 son parangonables, pero si que puede afirmarse que nuestro texto constitucional tan solo se ha reformado como respuesta a exigencias externas, concretamente, las europeas. En el camino han quedado otras reformas del texto planteadas

9 BOCG. Congreso de los Diputados, serie B, núm. 329-1, de 26/08/2011.

10 Se anunciaba que podría suspenderse la recepción de las cantidades procedentes de los fondos estructurales y de cohesión por parte de los Estados que no cumplan con estas recomendaciones de la Unión Europea sobre endeudamiento.

11 Reforma aprobada por las Cortes Generales en sesiones plenarias del Congreso de los Diputados, de 22 de julio de 1992, y del Senado, de 30 de julio de 1992, sancionada por el Rey el 27 de agosto, y publicada en el BOE núm. 207, de 28 de agosto de 1992.

12 En este sentido, ha subrayado J. PEREZ ROYO que la reforma «no es una reforma española sino europea, como también lo fue la de 1992 ...Lo que ocurre es que esta tiene un calado incomparablemente mayor y nos sitúa ante una limitación de soberanía mucho más visible. Pero así, con limitaciones de soberanía, es como se ha ido construyendo Europa», en «La Reforma Constitucional en perspectiva», El País, 5/09/2011. Asimismo, en «la Reforma del Articulo 135 CE», REDC, núm. 93/2011, págs. 198-202. 
desde dentro, tanto por las fuerzas políticas, como por la doctrina y por la ciudadanía; la mas relevante, desde nuestro punto de vista, la del Senado.

Este trabajo tiene por objeto analizar, desde una vertiente constitucional, la reforma operada en el artículo 135 de nuestra Constitución, abordando aquellas cuestiones que entendemos presentan aristas vidriosas como son, en primer término, la regulación constitucional del principio de estabilidad presupuestaria y la limitación del déficit de las Administraciones, que tiene consecuencias jurídico-constitucionales de hondo calado en el modelo de Estado proclamado constitucionalmente, particularmente en el ejercicio de la autonomía financiera de las CCAA. En segundo término, realizaremos un estudio crítico del procedimiento en que dicha reforma se ha llevado a cabo, mediante la declaración de urgencia, con lectura única.

\section{EL PRINCIPIO DE ESTABILIDAD PRESUPUESTARIA}

\section{Su recepción en el Derecho comunitario}

El éxito de la instauración de la Unión Económica y Monetaria dependía de que las finanzas de los Estados miembros estuvieran saneadas. Por ello, el Tratado de Maastricht, como hemos visto, convirtió en «fundamento de la constitución financiera de la Unión» ${ }^{13}$ las limitaciones al déficit y a la deuda; de ahí que el Protocolo anejo al Tratado, sobre determinación de déficits excesivos, fijo en un 3\% del PIB el límite que debían cumplir los Estados para implantar la moneda única.

Sin embargo, se quería asegurar que el compromiso con la estabilidad financiera no fuera sólo una condición de acceso a la Unión Económica y Monetaria y que, una vez alcanzada, los Estados no pudieran desecharla, sino que ésta se conservara con el objeto de dar estabilidad al Euro. Este compromiso se forjó con el Pacto de Estabilidad y Crecimiento $^{14}$ (PEC), firmado en Amsterdam en 1997, aunque tenía su origen en la propuesta formulada por el entonces Ministro alemán de Finanzas (Theo Waigel) en el Consejo Europeo celebrado en Madrid en el mes de noviembre de 1995. El PEC se convirtió en el instrumento para garantizar la disciplina presupuestaria de los Estados miembros, con el fin de evitar la aparición de déficits excesivos y limitar su nivel de deuda. Para asegurar estos objetivos establecía una serie de mecanismos preventivos y correctores en caso de incumplimiento, e implementaba unas obligaciones que los Estados debían cumplir: elaborar y presentar Programas de estabilidad para mantener a medio plazo el equilibrio presupuestario, y definir el calendario de aplicación y las sanciones del procedimiento de déficit excesivo. Ahondando en esta dirección, en junio 2000, el Consejo Europeo de Santa María de Feira, aconsejó a los Estados que mantuvieran niveles de déficit público inferiores al $3 \%$ del PIB.

13 RIVOSECCHI, G.: «El Gobierno económico de la Unión Europea», ReDCE núm.8/2007, pág.3.

14 Compuesto por la Resolución del Consejo sobre el Pacto de estabilidad y crecimiento, acordada en Ámsterdam el 17 de junio de 1997 y por los Reglamentos (CE) núms. 1466/1997, del Consejo, de 7 de julio de 1997, relativo al reforzamiento de la supervisión de las situaciones presupuestarias y la supervisión y coordinación de las políticas económicas, y 1467/1997, de 7 de julio de 1997, del Consejo, sobre aceleración y clarificación del procedimiento de déficit excesivo. 
Sin embargo, el PEC ha sido objeto de notables vaivenes e incumplimientos, que han alcanzado, incluso, a quienes lo habían impulsado, ya que en 2004 fue el Consejo el que decidió no seguir con el procedimiento de déficit excesivo para Francia y Alemania; decisión que fue avalada por el Tribunal de Justicia de la UE en la Sentencia de 13 de Julio de 2004, lo que llevó a la reforma del PEC en el año 2005 ${ }^{15}$. Sin embargo, la gravedad de la crisis económica y financiera ha obligado a plantear una nueva revisión del Pacto, ya que la mayoría de los Estados miembros están hoy en día con déficits excesivos ${ }^{16}$.

El Tratado de Funcionamiento de la Unión Europea (2007) consagra como principios rectores que vinculan tanto a los Estados Miembros como a la Unión: los precios estables, finanzas públicas y condiciones monetarias sólidas y balanza de pagos estable (art. 119.3). Además, el artículo 126 mantiene la obligación de los Estados miembros de evitar déficits públicos excesivos; confiriendo a la Comisión la facultad de supervisar la evolución de la situación presupuestaria y del nivel de endeudamiento público de los Estados miembros, así como la adopción por el Consejo de una serie de medidas en caso de incumplimiento. Ahora bien, la determinación de las herramientas concretas para hacer efectivo dicho principio de estabilidad presupuestaria corresponde a los Estados miembros.

\section{EL PRINCIPIO DE ESTABILIDAD PRESUPUESTARIA EN EL ORDENAMIENTO POSITIVO ESPAÑOL.}

El principio de estabilidad presupuestaria se implanta en nuestro Ordenamiento como una exigencia del derecho comunitario, materializándose positivamente a través de una ley ordinaria, la Ley 18/2001, de 12 de diciembre de Estabilidad Presupuestaria (vigente hasta enero de 2008). La ley descansaba sobre el principio de »estabilidad presupuestaria» (art. 3); estableciendo los principios rectores a los que debía adecuarse la política presupuestaria del sector público español para la consecución de la estabilidad y del crecimiento económicos en el marco de la Unión Económica y Monetaria; además, contenía los procedimientos necesarios para la aplicación efectiva del principio de estabilidad

15 El PEC se reformó en 2005, «con la intención de lograr dos objetivos: reforzar la parte preventiva del PEC y, al mismo tiempo, mejorar la eficacia en la aplicación del procedimiento de déficit excesivo (PED), teniendo en cuenta la situación económica específica de los distintos Estados miembros (EEMM) y evitando el automatismo en la aplicación del procedimiento». C. SERRANO LEAL Y B. MONTORO ZULUETA: «El Pacto de estabilidad y crecimiento. Las finanzas públicas en la zona euro» Boletín Económico de ICE N²905, del 16 al 28 de febrero de 2007, pág. 6. Asimismo, puede verse una cuidada y abundante información sobre estas reformas en I. CARRASCO MONTEAGUDO E I. PARDO GARCÍA «El Pacto de Estabilidad y Crecimiento. Implicaciones en Una Europa Ampliada», en Nuevas Tendencias en Política Fiscal, núm. 835/2007, trabajo en el que exponen que «Los cambios introducidos en 2005 en el PEC «han intentado que siga basado en normas como garantía para cumplir los compromisos y la igualdad de trato. De manera general se ha intentado remediar su aspecto pro cíclico, mejorar los procedimientos de déficit excesivo y definir el objetivo presupuestario de cada país en el medio plazo», pág.69.

16 Mediante la aprobación por el Parlamento Europeo del six-pack el día 28 de noviembre de 2011, Vid. la valiosa información sobre este proceso en DOMINGUEZ MARTINEZ, J.M. y LÓPEZ JIMENEZ, J.M.: «Estabilidad presupuestaria y reforma constitucional en España», Diario La Ley núm. 7760/2011, pág.3. Su objetivo principal es reforzar los mecanismos de vigilancia y de sanción del Pacto de Estabilidad y Crecimiento y avanzar, por consiguiente, hacia una mayor disciplina fiscal. 
presupuestaria, de acuerdo con los principios derivados del Pacto de Estabilidad y Crecimiento ${ }^{17}$. En relación con el tema objeto de análisis, la normativa establecía la exigencia de presupuestos equilibrados, entendiéndose por tales aquellos con previsión de déficit cero, o, en su caso, con superávit.

Previsión normativa que supone una mayor exigencia de disciplina presupuestaria de la regulada en el Derecho Comunitario; expresado gráficamente en palabras de Martín Queralt «entre evitar un déficit público excesivo y establecer un superávit presupuestario es evidente que hay una gran diferencia» ${ }^{18}$

El marco de la estabilidad presupuestaria se configuró con carácter básico, y, por tanto, de aplicación a todas las Administraciones públicas; ello exigía la actuación presupuestaria coordinada entre todas ellas, puesta al servicio de la política económica del Gobierno, con la finalidad de conseguir la imprescindible estabilidad económica interna y externa. Este marco de actuación hizo necesario contar, además, con una Ley Orgánica complementaria para, respetando el ámbito de autonomía financiera que el artículo 156.1 de la Constitución garantiza a las Comunidades Autónomas, se articulara la actuación coordinada de todas ellas; aprobándose con tal fin la Ley Orgánica 5/2001, de 13 de diciembre, que proclama como objetivo el establecimiento de los mecanismos jurídicos de cooperación entre el Estado y las Comunidades Autónomas para alcanzar la estabilidad presupuestaria (art. 1) ${ }^{19}$. La Ley 18/2001, ha sido posteriormente derogada por el Real Decreto Legislativo 2/2007, de 28 de diciembre, por el que se aprueba el texto refundido de la Ley general de estabilidad presupuestaria; y la Ley Orgánica 5/2001, de 13 de diciembre complementaria del Decreto ha sido modificada por la Ley Orgánica 3/2006, de 26 de mayo.

Así pues, el Real Decreto 2/2007, de 27 de diciembre y la LO 5/2001, de 13 de diciembre que lo complementa constituyen, hasta ahora, el marco normativo en este campo, en el que se consagran los principios de estabilidad presupuestaria; de plurianualidad; de transparencia, y el principio de eficiencia en la asignación y utilización de recursos públicos.

El principio de estabilidad presupuestaria tiene una doble configuración en función de los sujetos a los que afecta, así, en relación a los agentes que integran el sector público — la Administración General del Estado, las entidades de la Seguridad Social, las Comunidades Autónomas y los entes locales - se concibe como la situación de equilibrio o de superávit computada, a lo largo del ciclo económico, en términos de capacidad de financiación de acuerdo con la definición contenida en el Sistema Europeo de Cuentas Nacionales y Regionales, y en las condiciones establecidas para cada una de las Adminis-

17 Vid. Exposición de Motivos de la Ley.

18 MARTÍN QUERALT, J.B: «La constitucionalización del principio de estabilidad presupuestaria: ¿una reforma realmente necesaria?», Tribuna Fiscal núm. 252/2011, pág. 5.

19 La división de la regulación de esta materia en una ley ordinaria y en una ley orgánica responde a la recomendación realizada por el Consejo de Estado. «Esta recomendación, una vez atendida por el Gobierno, provocó la división del primitivo anteproyecto de Ley General de Estabilidad Presupuestaria en dos proyectos de ley. El Proyecto de Ley General de Estabilidad Presupuestaria fue «heredero» del anteproyecto de Ley General de Estabilidad Presupuestaria, aunque se desgajaron, incorporándose al Proyecto de Ley Orgánica que le es complementario, los preceptos que, de acuerdo con el dictamen del Consejo de Estado, debían revestir carácter de ley orgánica por contener los mecanismos jurídicos de cooperación entre el Estado y las Comunidades Autónomas al servicio del objetivo de estabilidad presupuestaria.», F. URÍA FERNÁNDEZ: «Una reflexión acerca de la constitucionalidad de las Leyes de Estabilidad Presupuestaria», Cuadernos de Derecho Público, núm. 12/2001, pág. 134 . 
traciones públicas (art. 3.1). Mientras que en relación con el resto de las entidades públicas empresariales, sociedades mercantiles y demás entes de derecho público vinculados o dependientes de la Administración del Estado, de las Administraciones de las comunidades autónomas o de las entidades locales, se entiende por estabilidad presupuestaria la posición de equilibrio financiero.

El encaje constitucional de la legislación española reguladora del principio de estabilidad presupuestaria ha sido confirmado recientemente por el Tribunal Constitucional; aunque, pese al complejo contenido de dicho principio, los reproches sobre su constitucionalidad se han centrado exclusivamente en la vulneración del principio de autonomía financiera de las Comunidades Autónomas y de las Corporaciones Locales. La Sentencia 134/2011, de 20 de julio ${ }^{20}$ ha sido la primera en la que el Tribunal Constitucional ha afirmado la inexistencia de vulneración de la autonomía de las CCA y de las Corporaciones locales por aplicación de la legislación en materia de estabilidad presupuestaria. A dicha Sentencia le siguen un número considerable de pronunciamientos, en los que se reitera la doctrina sentada en la primera: 157/2011, de 18 de octubre ${ }^{21}, 185 / 2011$, de 23 de noviembre, 195/2011 196/2011, 197/2011, 199/2011, de 13 de diciembre y 203/2011, de 14 de diciembre. Las Sentencias resuelven los diversos Recursos de Inconstitucionalidad planteados por los órganos legitimados de algunas Comunidades Autónomas contra la Ley 18/2001, así como LO 5/2001, por considerar que su regulación lesionaba su autonomía - política y financiera-, así como la de las Corporaciones Locales.

Con carácter previo, cabe decir, en relación con las normas objeto de impugnación, que si bien es cierto que Ley 18/2001, de 12 de Noviembre, ha sido derogada por el Real Decreto Legislativo 2/2007, de 28 de diciembre, por el que se aprueba el texto refundido de la Ley General de Estabilidad Presupuestaria y la Ley Orgánica 5/2001 ha sido modificada por la 3/2006, de 26 de mayo; el Tribunal ha considerado que no se pierde el objeto del recurso ya que el texto refundido de la Ley General de Estabilidad Presupuestaria, pone de relieve que la derogación que realiza de la Ley 18/2001 supone su sustitución por otra normativa que reproduce, aun con una redacción diferente y más

20 Recurso de inconstitucionalidad núm. 1451-2002, interpuesto por el Parlamento de Cataluña frente a diversos preceptos de la Ley 18/2001, de 12 de diciembre, General de Estabilidad Presupuestaria y de la Ley Orgánica 5/2001, de 13 de diciembre, complementaria de la misma..

21 Respectivamente: Recurso de inconstitucionalidad 1454-2002. Interpuesto por el Consejo de Gobierno del Principado de Asturias en relación con diversos preceptos de la Ley 18/2001, de 12 de diciembre, general de estabilidad presupuestaria. Recurso de inconstitucionalidad 1455-2002. Interpuesto por el Consejo de Gobierno del Principado de Asturias en relación con diversos preceptos de la Ley Orgánica 5/2001, de 13 de diciembre, complementaria de la Ley general de estabilidad presupuestaria. Sentencia 195/2011, de 13 de diciembre de 2011. Recurso de inconstitucionalidad 1460-2002. Interpuesto por el Consejo de Gobierno de la Generalitat de Cataluña en relación con diversos preceptos de la Ley 18/2001, de 12 de diciembre, general de estabilidad presupuestaria. Sentencia 196/2011, de 13 de diciembre de 2011. Recurso de inconstitucionalidad 1467-2002. Interpuesto por el Gobierno de Aragón en relación con diversos preceptos de la Ley 18/2001, de 12 de diciembre, general de estabilidad presupuestaria. Sentencia 197/2011, de 13 de diciembre de 2011. Recurso de inconstitucionalidad 1487-2002. Interpuesto por las Cortes de Aragón en relación con diversos preceptos de la Ley 18/2001, de 12 de diciembre, general de estabilidad presupuestaria y de la Ley Orgánica $5 / 2001$, de 13 de diciembre, complementaria a la Ley general de estabilidad presupuestaria. Sentencia 199/2011, de 13 de diciembre de 2011. Recurso de inconstitucionalidad 1505-2002. Interpuesto por sesenta y dos Diputados del Grupo Parlamentario Socialista del Congreso de los Diputados en relación con diversos preceptos de la Ley 18/2001, de 12 de diciembre, general de estabilidad presupuestaria 
amplia, las mismas cuestiones objeto de controversia. Y otro tanto ocurre respecto de la Ley Orgánica 3/2006, de 26 de mayo, que modifica parte de los preceptos recurridos de la Ley Orgánica 5/2001. De ahí que, puesto que «la normativa en relación con la cual se trabó el conflicto no es simplemente derogada, sino parcialmente sustituida por otra que viene a plantear en esencia los mismos problemas competenciales, la doctrina de este Tribunal avala la conclusión de la no desaparición del objeto del conflicto». Además, cuando «la normativa en relación con la cual se trabó el conflicto no es simplemente deroga$\mathrm{da}$, sino parcialmente sustituida por otra que viene a plantear en esencia los mismos problemas competenciales, la doctrina de este Tribunal avala la conclusión de la no desaparición del objeto del conflicto» ${ }^{22}$.

En segundo lugar, pese a que en todas las Sentencias se confirma la constitucionalidad del principio de estabilidad presupuestaria objeto de recurso; sin embargo, una cuestión de relieve constitucional distingue la primera de las Sentencias (134/2011) respecto de las demás. Y es que, las últimas resoluciones se producen cuando ya se ha reformado el artículo 135 de la Constitución, por lo que gozando el principio de estabilidad presupuestaria de reconocimiento constitucional, manifiesta el Tribunal que resulta claro, que «es a este nuevo canon de constitucionalidad al que hemos de atenernos ahora al dictar sentencia, pues es doctrina uniforme de este Tribunal que en el recurso de inconstitucionalidad no se fiscaliza si el legislador se atuvo o no, en el momento de legislar, a los límites que sobre él pesaban, sino, más bien, si un producto normativo se atempera, en el momento del examen jurisdiccional, a tales límites y condiciones.» ${ }^{23}$. Por tanto, el principio de estabilidad presupuestaria contenido en el artículo 135 de la Constitución cuenta ya con el reconocimiento del Tribunal Constitucional. Estamos, pues, «ante un mandato constitucional que, como tal, vincula a todos los poderes públicos y que por tanto, en su sentido principal queda fuera de la disponibilidad — de la competencia - del Estado y de las Comunidades Autónomas» (199/2011).

La Autonomía financiera de las Comunidades Autónomas ha de contemplarse en su doble vertiente: la de gasto, esto es, la libre disposición de los recursos, lo que implica que las CCAA puedan definir sus gastos en los correspondientes Presupuestos; y la de ingreso; implicando, en definitiva, «la plena disponibilidad de sus ingresos sin condicionamientos indebidos y en toda su extensión, para poder ejercer las competencias propias y, en especial, las que se configuran como exclusivas» (STC 135/1992, de 5 de octubre) ${ }^{24}$.

La normativa sobre estabilidad presupuestaria «alteró de modo radical el comportamiento fiscal de las CCAA, estableciendo reglas más estrictas» ${ }^{25}$, ya que su margen de actuación en la aprobación de sus presupuestos quedaba afectada en aras de la consecución

22 SSTC 134/ 2011, de 20 de julio; 87/1993, 329/1993, y 155/1996, entre otras.

23 STC 179/1998, de 19 de septiembre, FJ 2, y en el mismo sentido SSTC 135/2006, de 27 de abril, FJ 3, 1/2011, de 14 de febrero, FJ 2 y 120/2011, de 6 de julio, FJ 2.

24 Vid., además, el estudio de GARCIA MORILLO, J.; PEREZ TREMPS, P. Y ZORNOSA PEREZ, J.: Constitución y financiación autonómica, Tirant lo Blanch, Valencia, 1998. MEDINA GUERRERO, M., La incidencia del sistema de financiación en el ejercicio de las competencias de las Comunidades Autónomas, Centro de Estudios Constitucionales, Madrid, 1992, MARTIN QUERALT, J., »El sistema de financiación de las Comunidades autónomas: notas críticas», Palau 14.

25 C. MONASTERIO ESCUDERO Y R. FERNÁNDEZ LLERA: «Hacienda autonómica, reglas fiscales y modernización presupuestaria», Presupuesto y Gasto Público núm. 51/2008: 83-106 
del principio de estabilidad presupuestaria, pues también ellas deben acatar los compromisos adquiridos por el Estado en esta materia; además, porque la consecución de los objetivos de estabilidad confiere al Gobierno central un mayor protagonismo ya que es a él quien le corresponde fijar los objetivos de estabilidad, aprobándose, en su caso, posteriormente por las Cortes Generales.

Los reproches de inconstitucionalidad planteados por la CCAA ante esta afectación de sus competencias y de la libre configuración de los Presupuestos propios han recibido respuesta por parte del Tribunal Constitucional. Dicha doctrina constitucional configura, en términos limitativos, la libertad de establecer los presupuestos autonómicos en los siguientes parámetros: $1^{\circ}$, no tiene carácter absoluto; $2^{\circ}$, no excluye la existencia de controles; $3^{\circ}$, no todos los controles estatales tienen justificación; de modo que las intervenciones del Estado que no se manifiesten imprescindibles para asegurar la coordinación de la política autonómica en un determinado sector económico, suponen un condicionamiento indebido de dicha autonomía financiera.

Parámetros constitucionales sobre los que el Tribunal edifica la constitucionalidad del principio de estabilidad presupuestaria en nuestro Ordenamiento. Y ello con arreglo a los siguientes fundamentos jurídicos. En primer lugar, la concepción de la estabilidad presupuestaria como una orientación de la política económica general, que el Estado pue-

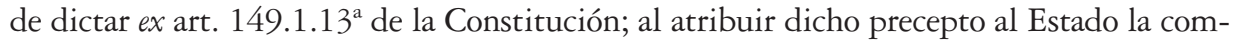
petencia sobre las bases y coordinación de la planificación general de la actividad económica, en tanto que competencia de dirección general de la economía que se proyecta en los diversos sectores de la misma y también en materia presupuestaria. En segundo lugar, la legitimidad del establecimiento unilateral por el Estado de límites presupuestarios en materias concretas, en forma de topes máximos, limitativos del gasto de las Administraciones Públicas, señaladamente de las CCAA; con base tanto en «la competencia estatal de dirección de la actividad económica general (ex art. 149.1.13) (STC 96/1990, FJ $3) »$, «en aras de la consecución de la estabilidad económica y la gradual recuperación del equilibrio presupuestario (STC 237/1992, FJ 3)», mediante la Ley de presupuestos, concebida como « vehículo de dirección y orientación de la política económica que corresponde al Gobierno [SSTC 27/1981, FJ 2; 76/1992, FJ 4 a), por todas] (STC 171/1996, FJ 2)»; como en «el principio de coordinación con la Hacienda estatal del art. 156.1 CE, con el alcance previsto en el art. 2.1 b) LOFCA, el cual exige a las Comunidades Autónomas la acomodación de su actividad financiera a las medidas oportunas que adopte el Estado tendentes a conseguir la estabilidad económica interna y externa, toda vez que a él corresponde la responsabilidad de garantizar el equilibrio económico general (SSTC 171/1996, FJ 2; 103/1997, FJ 1)»; estableciendo la limitación de la autonomía financiera en materia presupuestaria, al incidir ésta directamente en los objetivos de política económica. En tercer lugar, finalmente, la legitimidad constitucional del establecimiento por el Estado de topes generales en la elaboración de los presupuestos autonómicos, «toda vez que la política presupuestaria es un instrumento de la política económica de especial relevancia, a cuyo través incumbe al Estado garantizar el equilibrio económico general (STC 62/2001, FJ 4)», con base en los artículos 149.1.13 y 156.1 en conexión con el art. 149.1.14 CE.

El T.C. avala la constitucionalidad de la fijación por el Consejo de Política Fiscal y Financiera del objetivo de estabilidad presupuestaria correspondiente a cada una de las 
Comunidades Autónomas, pues «es una cuestión que por su naturaleza y alcance afecta, sin duda, a "la garantía del equilibrio económico, a través de la política económica general" (art. 2.1 b) LOFCAf y ha de ser adoptada,..." con carácter general y de forma homogénea para todo el sistema”».

\section{Contenido de la ReForma del ARTículo 135}

En el marco de esta doctrina que avala la constitucionalidad del principio de estabilidad presupuestaria, irrumpe en nuestro texto constitucional dicho principio, constitucionalizando las obligaciones derivadas del derecho comunitario en este ámbito, mediante la reforma del artículo $135^{26}$. Alcanzando con ello rango constitucional, y, en consecuencia, convirtiéndose en parámetro de constitucionalidad, al igual que ya lo eran los principios presupuestarios de unidad, universalidad y temporalidad, regulados en el art. 134.2 CE.

La justificación ofrecida por los proponentes de la reforma constitucional es estrictamente de naturaleza económica y política: la conveniencia de llevar el principio de referencia a la Constitución, con el objeto de fortalecer la confianza en la estabilidad de la economía española a medio y largo plazo, dado el escenario de la situación económica y financiera, marcada por una profunda y prolongada crisis. Por tanto, tal y como puede leerse en la Exposición de Motivos, la presente reforma del artículo 135 de la Constitución Española persigue garantizar el principio de estabilidad presupuestaria, vinculando a todas las Administraciones Públicas en su consecución; reforzar el compromiso de España con la Unión Europea; y, al mismo tiempo, procurar la sostenibilidad económica y social de nuestro país.

Y ello lo pretende con arreglo a la siguiente formulación jurídica:

En primer lugar, la reforma incorpora al artículo la sujeción de todas las Administraciones Públicas al principio de estabilidad presupuestaria (135.1). Dicho contenido, como hemos tenido ocasión de apreciar anteriormente, no es innovador, ya que el Decreto 2/2007 — por mor del Derecho Comunitario — prevé la aplicabilidad del principio en cuestión respecto de los grupos de agentes que integran el sector público: la Administración General del Estado, las entidades de la Seguridad Social, las Comunidades Autónomas y los entes locales. Ámbito, sobre el que el Tribunal Constitucional se ha pronunciado avalando su encaje constitucional.

26 Ciertamente, durante el proceso de elaboración de la Constitución española de 1978, el artículo 149 del Anteproyecto, contemplaba el principio de equilibrio presupuestario en relación con los Territorios Autónomos, al disponer que «(éstos) elaborarán su presupuesto anual con equilibrio de ingresos y gastos, sin perjuicio de la posibilidad de la formación de presupuestos extraordinarios financiados con cargo a sus recursos específicos o a los procedentes de operaciones de crédito». Sin embargo, esta previsión se suprimió en la votación del Informe de la Ponencia, por considerar que su contenido no exigía su inclusión en el texto constitucional, sino que podía regularse mediante ley ordinaria. El contenido de dicho precepto, tras el Informe de la Ponencia pasará a recogerse en el artículo 151, si bien con una nueva redacción: «Las Comunidades Autónomas elaborarán su presupuesto anual con equilibrio de ingresos y gastos, sin perjuicio de la posibilidad de la formación de presupuestos extraordinarios» (DSC Núm. 82, de 17 de abril de 1978); sin que hubiera enmiendas al Informe de la Ponencia. En el Debate, el Sr. Carro Martinez, en una enmienda in voce, sin oponerse a su inclusión, consideró que era un precepto excesivamente detallista, y que no debía tener rango constitucional. Se adhirió el Sr. Solé Turá, apuntando la conveniencia de suprimirlo, pudiendo ser motivo en su caso de regulación en una ley ordinaria. Del mismo modo, el Sr. Peces Barba manifestó su acuerdo, por lo que la enmienda de supresión del artículo 151 del texto de la Ponencia por unanimidad, con 24 votos (DSCG, Núm. 91, de 16 de junio de 1978, págs. 1692-1693. 
En segundo lugar, regula la prohibición de que tanto el Estado como las Comunidades Autónomas, incurran en un déficit estructural que supere los márgenes establecidos, en su caso, por la Unión Europea para los Estados Miembros; remitiendo a una Ley Orgánica la fijación de ese déficit estructural máximo permitido al Estado y a las Comunidades Autónomas, en relación con su producto interior bruto. Por su parte, las Entidades Locales deberán presentar equilibrio presupuestario (135.2).

En tercer lugar, el anterior artículo 135 se mantiene en el apartado 3, pero modifica el contenido preexistente ${ }^{27}$, ya que en su versión previa a la reforma el contenido del artículo se ceñía a la necesidad de que el Gobierno estuviera autorización por ley para emitir deuda pública o contraer crédito. La nueva redacción del precepto amplía el ámbito también a las Comunidades Autónomas, y añade que el volumen de deuda pública del conjunto de las Administraciones no pueda superar el valor de referencia establecido en el Tratado de Funcionamiento de la Unión Europea, es decir, el 60\% del PIB. Además, reformulando la anterior redacción, el pago de los créditos para satisfacer los intereses y el capital de la deuda pública de las Administraciones pasa a tener una prioridad absoluta. Esta si que constituye, verdaderamente, una innovación, ya que, como ha advertido Pisarello «esta previsión carece de parangón en el derecho constitucional comparado» ${ }^{28}$.

En cuarto lugar, la regulación aporta cierta flexibilidad, ya que, inspirándose en el modelo alemán ${ }^{29}$, pero de modo más abierto que éste, establece tres supuestos en los que dicho límite se puede superar: situación de catástrofe natural a la que el Estado no puede hacer frente, recesión económica, o situaciones de emergencia extraordinaria que escapen al control del Estado y perjudiquen considerablemente la situación financiera o la sostenibilidad económica o social del Estado; debiendo ser apreciadas dichas excepciones por la mayoría absoluta de los miembros del Congreso de los Diputados (135.4)

En quinto lugar, remite a una Ley Orgánica el establecimiento de los límites de déficit estructural y el volumen de deuda pública. Norma que ha de regular, en todo caso: a) la distribución de los límites de déficit y de deuda entre las distintas Administraciones Públicas, los supuestos excepcionales de superación de los mismos y la forma y plazo de corrección de las desviaciones que sobre uno y otro pudieran producirse; b) la metodología y el procedimiento para el cálculo del déficit estructural; c) la responsabilidad de cada Administración Pública en caso de incumplimiento de los objetivos de estabilidad presupuestaria.

Con ello se produce una elevación del rango de la ley reguladora, requiriéndose que sea Ley Orgánica, a diferencia de la existente hasta ahora que es ordinaria, y sustrayéndose con ello su regulación por Decreto Ley ${ }^{30}$.

27 Un estudio sobre el contenido del artículo 135 previo a la reforma puede verse en TEJERIZO LÓPEZ, J.M.: «Artículo 135: Deuda Pública,», en Comentarios a la Constitución española de 1978, Dr. ALZAGA VILLAAMIL, O., Edersa, Madrid, 1996, págs. 345-370.

28 «La priorización en términos absolutos -ni siquiera relativos- del pago de los créditos contraídos para el pago de la deuda pública ignora la posibilidad de que estos puedan ser usurarios, ilegítimos, o simplemente de que puedan renegociarse. En rigor se trata de una previsión que prima la satisfacción de ciertas deudas externas sobre otras internas», G. PISARELLO «Reforma constitucional y crisis», Jueces para la democracia, ISSN núm.72/2011, págs. 3.

29 Vid. con detalle EKKEHART REIMER; «La crisis financiera como oportunidad político-constitucional., ob. cit. págs.103-105

30 La reforma operada en este precepto ha sido calificada por E. ALVAREZ CONDE en los siguientes términos: «texto farragoso con una fórmula jurídica excesivamente abierta que puede condicionar su propia efi- 
La Disposición adicional única, en su apartado 1 prevé que esta Ley Orgánica deba estar aprobada antes del 30 de junio de 2012. Y en cumplimiento de dicho mandato constitucional en estos últimos días el Consejo de Ministros ha acordado remitir al Consejo de Estado el Anteproyecto de Ley Orgánica de Estabilidad Presupuestaria y Sostenibilidad Financiera de las Administraciones Públicas. Texto respaldado por las Comunidades Autónomas en el Consejo de Política Fiscal y Financiera y las entidades locales, en la Comisión Nacional de Administración Local. ${ }^{31}$

\section{EL CONTROVERTIDO PROCEDIMIENTO DE REFORMA}

Como hemos apuntado anteriormente, la reforma constitucional del artículo 135 de la Constitución se ha sustanciado apresuradamente, a través de un procedimiento que ha sido cuestionado en diversos ámbitos, tanto políticos, como académicos ${ }^{32}$.

\section{EL CONTEXTO DE LA REFORMA}

La reforma constitucional se ha llevado a cabo por las dos fuerzas políticas mayoritarias, sin el consenso de otros grupos parlamentarios, mediante el procedimiento de urgencia, con lectura única y sin someterse a referéndum. Un procedimiento, que no puede tacharse de inconstitucional, pero que, por el contrario, nos plantea serias dudas sobre su acierto o idoneidad. Y es que, tal y como acertadamente ha sostenido el Consejo de Estado, partiendo de que la adaptabilidad de las constituciones es un valor positivo para su pervivencia, el acierto en los procesos de revisión constitucional depende de la conjunción de varios factores, de entre los que cabe destacar «que las alternativas propuestas hayan sido suficientemente maduradas y sean consecuencia de un diálogo sostenido y sereno entre las fuerzas políticas con la sociedad» [y que] «se genere en torno a las modificaciones

cacia normativa» [con una] técnica normativa sumamente defectuosa», «la Reforma del Articulo 135 CE», REDC, núm. 93/2011, pág. 163. Por su parte J. DE ESTEBAN la ha calificado de «chapucera aunque necesaria», pág. 197.

31 En términos generales, el texto garantiza la adaptación continua y automática a la normativa de la gobernanza económica europea y recoge, entre otros requerimientos: La obligación para todas las Administraciones Públicas de presentar equilibrio estructural. El establecimiento de un límite de deuda como garantía de sostenibilidad presupuestaria. La formulación de un marco presupuestario a medio plazo en el que se enmarcará la elaboración del presupuesto y a través del cual se garantizará una programación presupuestaria coherente con los objetivos de estabilidad y de deuda pública. La incorporación de actuaciones preventivas de alerta temprana y de corrección automática. El refuerzo de los mecanismos sancionadores en los que se tendrán en cuenta, en línea con la normativa europea, la reincidencia y la gravedad de los incumplimientos.

32 En este sentido apuntaba M. ARAGÓN REYES que «las prisas, sobre todo en un asunto tan fundamental como la reforma de la Constitución, suelen ser muy malas consejeras» «la Reforma del Articulo 135 CE», REDC, núm. 93/2011, pág.172, pues como ya manifestó en su día »la excesiva agilización del procedimiento legislativo parlamentario iría en detrimento del principio democrático pluralista, principio que exige la amplitud de la discusión y del debate público parlamentario y principio que es hoy la mas sólida fundamentación del concepto de ley» ARAGÓN REYES, M., »La función legislativa de los Parlamentos y sus problemas actuales», en El Parlamento y sus transformaciones actuales, GARRORENA MORALES, A. (ed.), Tecnos, Madrid, 1990, pg.140 
un consenso asimilable al que concitó el texto que se quiere reformar ${ }^{33}$. Factores que han estado ausentes en el actual proceso de reforma constitucional objeto de análisis.

Dicha ausencia revela que el procedimiento parlamentario se ha plegado a una decisión política en aras de calmar a los mercados; pero no que respondiera a exigencias jurídicas verdaderamente apremiantes. En principio, los plazos marcados por los líderes europeos no eran imperiosos, ya que el margen para la determinación del déficit concluye a finales de 2012, y el compromiso de estabilidad presupuestaria debe cumplirse en 2020. Además, nuestro ordenamiento jurídico no estaba yermo de normativa sobre la que anclar las medidas pretendidas, pues, además del carácter vinculante del PEC, la Ley General de Estabilidad Presupuestaria ofrecía el soporte jurídico suficiente para la implantación de las medidas encaminadas a conseguir la estabilidad presupuestaria. Máxime cuando el Tribunal Constitucional se ha pronunciado en julio de 2011 confirmando el encaje constitucional de dicha legislación.

Ahora bien, si consideramos que la decisión política — acertada o no- de reformar la Constitución para constitucionalizar el principio de estabilidad presupuestaria era la que definitivamente iba a imperar, los tempus permitían cabalmente acudir a procedimientos parlamentarios no tan expeditivos y acelerados como los que se han seguido. Sin embargo, ello encontraba un escollo: la convocatoria de las elecciones generales y la disolución de las Cámaras era eminente y la reforma constitucional debía, por razones de oportunidad, de naturaleza económica y política, aprobarse antes de que finalizara la legislatura. El anuncio tan precipitado de la reforma constitucional coincidió con un momento de máxima dificultad de la situación económica y financiera, con alta tensión en los mercados, que condujo a la inusual compra de deuda a España y a Italia por el Banco Central Europeo; pero dicha compra estaba sujeta a unas condiciones ya que se conminaban a los Jefes de Gobierno español e italiano a la adopción de decisiones de gran envergadura ${ }^{34}$. Estas exigencias, junto con la precitada orden de los dos líderes europeos de reformar sus Constituciones, condujo a que el entonces Presidente del Gobierno J. L. Rodriguez Zapatero, anunciara la reforma constitucional en el Pleno extraordinario del Congreso de los Diputados celebrado el día 23 de agosto. Se hacía eco, así, de la propuesta formulada un año antes por el líder del Partido Popular Mariano Rajoy, quien, por convicción ideológica y por mimetismo con Alemania, entendía que la Constitución española debía seguir el modelo de la Ley Fundamental de Bonn.

Esta premura por ofrecer respuestas contundentes que tranquilizaran a los mercados ha sido el justificante ofrecido por los dos grupos políticos mayoritarios para acometer la

33 Los otros se concretan en que «los cambios a introducir respondan a demandas consistentes y que busquen resolver problemas o insuficiencias ampliamente reconocidas. Y en que sean limitados y prudentes para no alterar el equilibrio en el que se sustenta el texto constitucional». Informe sobre modificaciones de la Constitución española, $\mathrm{N}^{\circ}$ : E $1 / 2005$ febrero 2006

34 En una Carta fechada el día 4 de ese mes y firmada por el entonces presidente del BCE, Jean-Claude Trichet y por el gobernador del Banco de España, Miguel Ángel Fernández, en la que la institución financiera conminaba al Gobierno a aprobar determinadas medidas anticrisis. En Italia, Berlusconi, menos temeroso del coste electoral de la adopción de medidas de fuerte reajuste, presentó en su Parlamento la carta del BCE para que los italianos conocieran las medidas de ajuste impuestas desde Bruselas, anunciando la adopción de medidas draconianas, que hasta la fecha, no se han materializado. 
vertiginosa reforma del texto constitucional ${ }^{35}$. En efecto, la reforma del artículo 135 de la Constitución se ha tramitado en menos de un mes: el día 26 de agosto, tres días después del anuncio de la reforma por el Presidente del Gobierno en el Congreso, se presentó la Proposición de reforma constitucional ante la Mesa del Congreso ${ }^{36}$, y en el Boletín Oficial del Estado de 27 de septiembre ${ }^{37}$, se publicó el texto de la reforma aprobado y su entrada en vigor.

\section{El iter PARLAMENTARio}

\section{a) El consenso entre las «dos» fuerzas políticas mayoritarias}

Desde que se anunciara la reforma constitucional del Artículo 135, ésta ha sido objeto de un encendido debate, contando con la oposición de la mayoría de las fuerzas políticas con representación parlamentaria, centrado, tanto en cuestiones de forma como de fondo ${ }^{38}$.

Las mayores críticas de contenido han apuntado a la repercusión del contenido de la reforma sobre el modelo de organización territorial del Estado, al condicionar la autonomía financiera de las CCAA; así como a su vertiente social, ya que se valora como una medida neoliberal que puede afectar a las políticas sociales; en esta línea se apuntaba que la reforma implica una sustitución de la soberanía de los ciudadanos por la de los mercados, implicando una «Amputación del Estado del Bienestar». Asimismo, se ha remarcado su innecesaridad ya que el Pacto de Estabilidad y Crecimiento Europeo ya contenía las medidas que se pretendían implementar en el texto constitucional.

Pero, todos los grupos con representación parlamentaria, excepto los proponentes ${ }^{39}$, han coincidió en reprobar el procedimiento de reforma seguido, al considerarlo un atropello a los procedimientos parlamentarios. En este sentido, aún compartiendo el principio de estabilidad presupuestaria, grupos como CIU se opusieron al procedimiento por considerar que rompía el consenso constitucional que había presidido la elaboración de la Constitución ${ }^{40}$.

35 Circunstancias que conducen a J. TAJADURA TEJADA a mantener la oportunidad de la reforma, en «Reforma constitucional e integración europea», así como advertir las ventajas de la constitucionalización del Derecho Comunitario, Claves de Razón Práctica, núm. 216 /2011

36 Proposición de Reforma del artículo 135 de la Constitución Española, publicada en el »Boletín Oficial de las Cortes Generales», serie B, núm. 329-1, de 26 de agosto de 2011.

37 BOE Núm. 233 Martes 27 de septiembre de 2011.

38 La reforma anunciada ni siquiera contaba con el respaldo del mismo grupo socialista, que, en un principio, se inclinaba por incluir el techo del déficit en la Ley de Estabilidad Presupuestaria; de hecho, esta era la postura que se desprendía de los Acuerdos adoptados en el Consejo de Política Fiscal y Financiera, de 15 de julio de $2009^{38}$, y la que se había manifestado públicamente por algunos de sus dirigentes.

39 Aunque en las filas del Partido Socialista había disidentes.

40 El representante de CIU Duran i Lleida manifestaba que «Esta actitud de los dos grandes partidos de no contar con nadie significa una ruptura del proceso constituyente», calificándola como una reforma realizada con nocturnidad y alevosía. Desde la doctrina también se ha criticado el procedimiento, así R. BLANCO VALDÉS afirma que aun estando de acuerdo con fijar un «límite de gasto a las administraciones públicas que contribuya a evitar que vuelva a producirse un desastre como el que vivimos actualmente, creo que hacerlo como se ha hecho, en la forma y en el fondo, constituye un disparate jurídico y político», en «Un Disparate Jurídico y Político», ABC, 27/08/2011. 
En relación con el procedimiento, con carácter previo conviene aclarar que, la reforma constitucional no se ha sometido a la consideración del Consejo de Estado, ya que se ha presentado como una Proposición de reforma, y no como Proyecto de reforma. Y es que, tras la reforma introducida por la Ley Orgánica 3/2004, de 28 de diciembre, por la que se modifica Ley Orgánica 3/1980, del Consejo de Estado, se introduce con carácter preceptivo la consulta al Consejo en Pleno sobre los anteproyectos de reforma constitucional cuando la propuesta no haya sido elaborada por el propio Consejo de Estado (artículo 21.1). Sin embargo, esta exigencia, como puede advertirse, se refiere sólo a los proyectos y no a las proposiciones. De ahí la ausencia del pronunciamiento del Consejo de Estado para proceder en este caso a la reforma de la Constitución ${ }^{41}$.

\section{b) La vía ordinaria de revisión del artículo 167 CE}

La reforma del Artículo 135 se ha lleva a cabo, de acuerdo con las previsiones constitucionales, a través del procedimiento ordinario previsto en el artículo 167 de la Constitución, ya que se encuentra en el Título VII del texto constitucional, y, por tanto, fuera de las materias y de los preceptos para los que se reserva el procedimiento agravado del artículo 168 de la Constitución.

Procedimiento que ha sido cuestionado mediante la formulación de una enmienda a la totalidad ${ }^{42}$, sosteniendo que la reforma propuesta del artículo 135 supone una modificación encubierta del Título Preliminar de la Constitución española, en especial de su artículo 1.1, que, además, implica una merma de los derechos fundamentales; concluyendo por ello que la reforma debía haberse tramitado a través del procedimiento agravado previsto en el artículo 168.

El rechazo de la enmienda ha ocasionado la interposición del Recurso de Amparo 5241-2011 por los firmantes de la misma, que ha sido resuelto por el Auto de 13 de enero del Tribunal Constitucional, en el que declara la conformidad del procedimiento de reforma a través de la vía ordinaria del artículo 167; partiendo de que la Mesa del Congreso de los Diputados «con escrupulosa sujeción a lo dispuesto en los artículos 167 y 168 CE», sólo podía calificar la reforma del artículo 135 como objeto del procedimiento ordinario «sin plantearse eventuales conexiones del precepto objeto de reforma con otros preceptos o apartados de la Norma Suprema que sí debian ser objeto del procedimiento agravado». Resolución sobre la que posteriormente nos detendremos.

41 Parecer del Consejo de Estado que ya se había emitido al pronunciarse sobre el Anteproyecto de Ley de Estabilidad Presupuestaria (Dictamen $n^{\circ}$ 4/2001). Si bien, en este caso se refería a legislación ordinaria, mientras que en el presente caso estamos hablando de una reforma constitucional.

42 Enmienda Núm. 4 formulada por el Grupo Parlamentario de Esquerra Republicana-Izquierda UnidaIniciativa per Catalunya presenta la enmienda de totalidad con texto alternativo a la Proposición de Ley de reforma del artículo 135 de la Constitución Española, presentada por los Grupos Parlamentarlos Socialista y Popular en el Congreso, mediante el que pretenden la reforma del artículo 135 de la Constitución Española, cuya tramitación han acordado se realice por un procedimiento que asegura el mínimo debate y trabajo parlamentario y el mínimo contraste y participación social. En ella se afirma que el proceso para la aprobación de la reforma contenida en la enmienda a la totalidad es el determinado por el artículo 168 de la Constitución Española, toda vez que las materias que han de ser objeto de reforma afectan a los derechos y deberes fundamentales de las personas que habitan en nuestro país, y por afectar al Título Preliminar. BOCG. Congreso de los Diputados, serie B, núm. 329-3, de 05/09/2011 
Una vez resuelta esta cuestión, conviene anotar que el artículo 167 de la Constitución no establece ninguna especialidad procedimental, más allá de que los proyectos de reforma constitucional deberán ser aprobados por una mayoría de tres quintos de cada una de las Cámaras. Mayoría cualificada que el texto constitucional exige en contadas ocasiones (artículos 122 y 159) para la elección parlamentaria de miembros del Consejo General del Poder Judicial y de los Magistrados del Tribunal Constitucional; materias en las que el constituyente quiso provocar una acuerdo reforzado entre las fuerzas políticas. Por otro lado, el artículo 75.3 CE excluye la reforma constitucional de la delegación que las Cámaras pueden hacer a favor de las Comisiones Legislativas Permanentes.

La ausencia de normas procedimentales concretas en el artículo 167 de la Constitución plantea lagunas e interrogantes que tampoco colma el Reglamento del Congreso de los Diputados, ya que regulándose en el Título V (Del procedimiento legislativo), en su Capítulo III — de las especialidades en el procedimiento legislativo-, Sección $4^{a}$ (de la revisión y de la reforma constitucionales), el artículo 146 tan sólo prevé como especialidad respecto de los proyectos y proposiciones de ley que las propuestas de reforma constitucional deben suscribirse por dos Grupos Parlamentarios o por una quinta parte de los Diputados. Ninguna previsión más se establece en el texto del Congreso.

El procedimiento está desarrollado con carácter específico en el Reglamento del Senado en el Título Quinto «Del procedimiento de revisión constitucional» (arts. 152 a 159), que regula, por un lado (Capítulo I), el procedimiento cuando la iniciativa de reforma parte de esta Cámara, y en el que, los plazos y el número y duración de los turnos de palabra serán los que determine el Presidente, de acuerdo con la Mesa y oída la Junta de Portavoces; por otro (Capítulo II) el procedimiento cuando la revisión proviene del Congreso de los Diputados parece más minucioso; no obstante, la declaración por el Congreso de determinados procedimientos vincula a la Cámara Alta, por lo que ha de ajustarse a las condiciones que el Congreso ha determinado.

\section{c) Lectura única y urgencia}

En el caso que nos ocupa, un vez iniciado el iter parlamentario mediante la presentación de la proposición de reforma por los Grupos Parlamentarios Socialista y Popular ${ }^{43}$, el Pleno de la Cámara, en su sesión del día 31 de agosto, acordó tomar en consideración la Proposición de Reforma del artículo 135 de la Constitución Española, así como su tramitación directa y en lectura única, según el artículo 150 del Reglamento. ${ }^{44}$

El procedimiento de lectura única está regulado en el artículo $150^{45}$ del Reglamento del Congreso de los Diputados y en 129 del Reglamento del Senado. La lectura única afecta a los proyectos o proposiciones de ley, ya tomados en consideración, cuya naturaleza

43 BOCG. Congreso de los Diputados, serie B, núm. 329-1, de 26/08/2011

44 BOCG. Congreso de los Diputados, serie B, núm. 329-2, de 31/08/2011.

45 En el Reglamento del Congreso, se considera una especialidad en el procedimiento, regulándose en el Título V (Del procedimiento legislativo), Capítulo Tercero (De las especialidades en el procedimiento legislativo). Mientras que en el Senado está considerado como un procedimiento especial, regulándose en el Título Cuarto (Del procedimiento legislativo), Capítulo Segundo (De los procedimientos legislativos especiales), Sección primera. De la tramitación de un proyecto de ley en lectura única. Para un estudio más detallado vid. $\mathrm{M}^{\mathrm{a}} \mathrm{A}$. GARCÍA MARTÍNEZ, El procedimiento legislativo, Congreso de los Diputados, Madrid, 1987. 
lo aconseje o la simplicidad de su formulación lo permita. Ante esta formulación, doctrinalmente parece claro que dicho procedimiento se debe aplicar cuando el asunto no ofrece mucha dificultad, pero, también cuando existe un consenso parlamentario suficiente para resolver problemas de índole política que exigen una rápida solución ${ }^{46}$; o en casos de textos más simples y menos discutidos políticamente ${ }^{47}$; o de extrema simplicidad $^{48}$; o cuando exista un amplio consenso parlamentario sobre la materia ${ }^{49}$.

La reforma del artículo 13 de la Constitución se realizó también por el procedimiento de lectura única ${ }^{50}$; sin embargo las circunstancias fácticas en aquel caso evidenciaron la existencia de consenso y la simplicidad de su formulación; por lo que en ningún momento se cuestionó el recurso a este procedimiento. La reforma del artículo 135 no puede considerarse que cumpla con el presupuesto de la simplicidad; y no ha habido el mismo consenso que en el caso anterior; ahora bien, la fórmula utilizada por el artículo 150 del Reglamento «cuando su naturaleza lo aconseje» permite dar cobertura jurídica a este caso concreto; aunque no puede calificarse de simple o poco discutido políticamente. En todo caso, cabría acogerse a la existencia de un consenso «suficiente» para resolver problemas que exigen una rápida solución. Por lo que la tacha de inconstitucionalidad sería cuestionable; aunque si la de la idoneidad, cuando el consenso ha sido «suficiente» pero no el aconsejable para liquidar una reforma constitucional en un mes.

La propuesta de someter un texto a lectura única corresponde a la Mesa, que deberá oír previamente a la Junta de Portavoces, y la decisión corresponde al Pleno. Se trata de un procedimiento que reduce considerablemente la tramitación de los textos, ya que suprime determinados trámites, esencialmente, la fase de Comisión, y, por tanto, se debate sólo en Pleno, siendo de aplicación al respecto las normas sobre debate y votación de totalidad.

46 ALONSO DE ANTONIO, J.A. Y A.L: Introducción al Derecho Parlamentario, Dykinson, Madrid, 2002, pág. 178. Por su parte, GARCÍA-ESCUDERO MÁRQUEZ, P., en su trabajo sobre «El procedimiento legislativo en las Cortes Generales: regulación, fases y tipos», Teoría y Realidad Constitucional, n 16/ 2005, pág. 238, considera que el procedimiento de lectura única viene referido en los Reglamentos a tres casos: $1^{\circ}$ ) «Para la tramitación de proyectos o proposiciones de ley muy breves y sencillos, básicamente consensuados, que sería la previsión reglamentaria», $2^{\circ}$ ) «Para la tramitación de proyectos o proposiciones sobre los que recae acuerdo unánime de tramitación particularmente acelerada por urgencia política en la promulgación de la ley (por ejemplo, medidas para víctimas del terrorismo)», y $3^{\circ}$ ) «Cuando se opta por este procedimiento, o así lo impone una ley, por introducirse un elemento pactista en la elaboración del proyecto o proposición (por ejemplo, las modificaciones de la LORAFNA o los acuerdos sobre concierto y cupo económico vasco en las Comunidades Autónomas de Navarra y País Vasco). En este último caso, sobre la que el Tribunal Constitucional ha tenido ocasión de pronunciarse cuando justifica la aplicación del procedimiento de lectura única «en la naturaleza negociada y paccionada de los textos tramitados conforme a esta variante procedimental» (STC 27/2000, de 31 de enero, f.j. $5^{\circ}$ ). Vid., asimismo, GÓMEZ LUGO, Y.: «La tramitación legislativa en lectura única», InDret 4/2007, autora que ha abordado pormenorizadamente el tratamiento de este procedimiento.

47 BUSTOS, R.: «La función legislativa», en El Congreso de los Diputados en España: funciones y rendimientos, Martinez, A. (ed.), Tecnos, Madrid, 2000, pág.64.

48 RUBIO LLORENTE, F.: «El Procedimiento legislativo en España», La Forma del Poder, CEC, Madrid, 1993, pág. 298.

59 ALVAREZ CONDE, E.: Curso de Derecho Constitucional, Tecnos, Madrid, 2006, pág. 175.

50 «En esta ocasión la celeridad venía impuesta por exigencias ajenas a las Cámaras, principalmente, por la necesidad de ratificar el Tratado de Maastricht y dar cumplimiento a la declaración vinculante del Tribunal Constitucional reconociendo la contrariedad entre la redacción de la norma convencional y el artículo 13.2 CE. Por tanto, ambos factores externos y sobrevenidos a la institución parlamentaria condicionaban la premura de la reforma constitucional», Gómez Lugo, Y.: «La tramitación...», pág. 10. 
Esta especialidad procedimiental excluye las votaciones de las enmiendas al articulado, ya que la limitación se traduce concretamente en la imposibilidad de presentar propuestas de modificación al articulado. Ello provoca «enervar» las normales facultades de enmienda y discusión de los parlamentarios ${ }^{51}$ y, en consecuencia, una limitación del derecho de participación de las minorías parlamentarias, ya que «desaparece la posibilidad de negociación y transacción política sobre el texto originario, así como la eventualidad de proponer alternativas al mismo durante el transcurso de la iniciativa por la Comisión ${ }^{52}$.

Por otro lado, el procedimiento de urgencia ${ }^{53}$ reduce los plazos de duración a la mitad de los establecidos con carácter ordinario. Su petición corresponde al Gobierno, a dos Grupos parlamentarios ${ }^{54}$ o a una quinta parte de los diputados, debiéndolo acordarlo la Mesa $^{55}$. «Se trata además de un procedimiento de abreviación estrictamente temporal, en cuanto actúa exclusivamente sobre los plazos establecidos con carácter general para reducirlos a la mitad, sin supresión ni modificación de trámites. Su sencillez hace, por tanto, que sea el procedimiento abreviado más utilizado» ${ }^{56}$.

Finalmente, El Pleno del Congreso de los Diputados en su sesión del día 2 de septiembre de 2011 ha aprobado con 316 votos a favor y 5 en contra, la Proposición de Reforma del artículo 135 de la Constitución Española de acuerdo con lo establecido en el artículo 167 de la Constitución, y habiéndose obtenido, en votación final, la mayoría de tres quintos prevista en el mencionado precepto constitucional. ${ }^{57}$ Mientras que el Pleno del Senado ha aprobado igualmente dicha Proposición de Reforma del artículo 135 de la Constitución Española, en su sesión del día 7 de septiembre de 2011 la mayoría de tres quintos prevista en el citado precepto constitucional, sin introducir modificaciones al texto remitido por el Congreso de los Diputados. ${ }^{58}$

51 SANTAOLALla LÓPEZ, F.: Derecho Parlamentario Español, Espasa, Madrid, 1990, pág. 285 y ss. Vid. además, VISIEDO MAZÓN, F.J. y SORIANO HERNÁNDEZ, E.: Las enmiendas en el procedimiento legislativo, Aelpa, 2000, págs. 127 y ss.

52 GÓMEZ LUGO, Y.: «La tramitación legislativa en lectura única», concreta que «la especialidad procedimental consiste en la omisión de las lecturas sucesivas a las que se somete el texto durante la tramitación parlamentaria para realizar una única deliberación que se llevará a cabo en el Pleno de la Cámara. En este supuesto se suprimen los trámites parlamentarios que se desarrollan en sede de Comisión; es decir, la aplicación de este procedimiento implica que todos los actos que lo integran van tener lugar en sede plenaria, suprimiendo aquellos que en el iter ordinario se celebran en Comisión y Ponencia», ob. cit. pág.4.

53 Previstos el Capítulo sexto (De la declaración de urgencia, artículos 93 y 94) del Título IV, relativo a las Disposiciones generales de funcionamiento. Mientras que en el Reglamento del Senado está considerado como un procedimiento especial, previsto en el Capítulo Segundo (De los procedimientos legislativos especiales), Sección tercera (Del procedimiento de urgencia) (arts. 133 a 136).

54 Trámite de urgencia avalado por PSOE, PP y UPN; en este caso el diputado socialista Antonio Gutiérrez rompió la disciplina de voto y rechazó el texto.

55 BOCG, serie B, núm. 329-2, de 31/08/2011.

56 P. GARCÍA-ESCUDERO MÁRQUEZ : «El Procedimiento Legislativo en las Cortes Generales...», ob. cit. pág. 22

57 BOCG. Congreso de los Diputados, serie B, núm. 329-4, de 06/09/2011. votos a favor los diputados del PSOE presentes en el hemiciclo (excepto Antonio Gutiérrez), y José Manuel Bar Cendón, que se equivocó, el PP y UPN. Votaron en contra los dos diputados de Coalición Canaria y la líder de UPyD, Rosa Díez. Ana María Oramas y Fernando Ríos (CC); mientras que los diputados de ERC, ICV, BNG y NaBai abandonaron el salón de plenos al llegar la votación. Duran i Lleida afirmaba: »Si no hemos estado en el consenso ni en el diálogo tampoco estamos en las votaciones».

58 BOCG. Senado, serie I, núm. 108-738, de 08/09/2011. Con 3 votos en contra de dos senadores de Coalición canaria y 1 del senador de Foro Asturias. Se ausentaron del hemiciclo los tres representantes de ERC y 
De acuerdo con lo previsto en el artículo 167.3 de la Constitución, una vez aprobada la reforma por las Cortes Generales, será sometida a referéndum para su ratificación cuando así lo soliciten, dentro de los quince días siguientes a su aprobación, una décima parte de los miembros de cualquiera de las Cámaras. En cumplimiento de dicho mandato constitucional, las Presidencias de las Cámaras hicieron pública la apertura del plazo ${ }^{59}$, sin que en ninguna de las Cámaras se alcanzara la mayoría requerida ${ }^{60}$.

\section{d) El cuestionamiento del procedimiento en sede constitucional}

En el marco de un procedimiento de reforma urgente, con lectura única, de las 24 enmiendas presentadas en el Congreso y 29 en el Senado, ninguna obtuvo el respaldo favorable; provocando que el procedimiento por el que se ha llevado a cabo la reforma constitucional haya sido objeto de impugnación mediante la interposición del Recurso de Amparo ante el Tribunal Constitucional núm. 5241-2011, por considerar, entre otras razones, que la reducción de plazos para la presentación de enmiendas lesiona el derecho al ejercicio de las funciones parlamentarias regulado en el artículo 23.2 de la Constitución ${ }^{61}$.

El Pleno del Tribunal, que avocó el conocimiento del Recurso de Amparo, resuelve la inadmisión mediante Auto 9/2012 de 13 de enero, considerando que no se aprecia lesión en la determinación del procedimiento de lectura única, ya que considera que ni de la lectura del artículo 146 ni del 150 RCD, ni de la Constitución, se advierte que la aprobación de la reforma constitucional haya quedado excluida de dicho procedimiento, pues estas normas no establecen materias vedadas a dicha tramitación; además, la adopción de dicho procedimiento no se ha debido a la voluntad de la Mesa del Congreso de los Diputados, sino al Pleno de la Cámara mediante la oportuna votación. En relación con la participación de los recurrentes en el procedimiento, entiende el Tribunal, que éstos «han tenido la oportunidad de intervenir en la fase plenaria durante el trámite de toma .en consideración y de oponerse mediante el oportuno voto a la misma, en la tramitación de la proposición mediante el controvertido procedimiento y, ulteriormente, en la propia aprobación de la iniciativa de reforma».

el del BNG, y permanecieron en el escaño son participar en la votación los representantes de CIU, PNV e ICV. Dos senadores socialistas que no estaban de acuerdo con esta medida no acudieron a la Sesión: Imanol Zubero y Roberto Lertxundi

59 BOCG. Senado, serie I, núm. 108-682, de 08/09/2011. BOCG. Congreso de los Diputados, serie B, núm. 329-5, de 08/09/2011; BOCG. Congreso de los Diputados Núm. B-329-6 de 10/09/2011 Pág.: 1 Apertura del plazo previsto en el artículo 167 de la Constitución Española (corrección de error)

60 BOCG. Congreso de los Diputados, serie B, núm. 329-7, de 28/09/2011. BOCG. Senado, serie I, núm. 121-1111, de 27/09/2011. En el Congreso solo lo solicitaron 19 diputados (6 PNV, 3 de ERC, dos de IU-ICV, 2 del GNG, 2 del Grupo Socialista, 2 de Coalición Canaria 1 PUyD, 1 Nafarroa-Bai.

61 Los demandantes entienden que las consecuencias del procedimiento parlamentario que se ha seguido en este particular conducen a: «Eludir la negociación previa de la reforma constitucional, dificultando la búsqueda de consenso y reduciendo las facultades de participación de los Diputados. Eludir la transparencia en la explicación y el contraste de opiniones sobre las consecuencias de la reforma. Evitar un debate en profundidad en la Comisión Constitucional. Dificultar el trabajo parlamentario de los Diputados que no han aceptado el acuerdo de los grupos promotores de la iniciativa. Evitar el debate y aportaciones de Comunidades Autónomas y Ayuntamientos, a quienes afecta directamente la reforma constitucional acometida. Evitar el referéndum que permitiera conocer »la opinión del pueblo español» sobre la reforma que de esta manera aparecerá como impuesta». 
La urgencia esta, igualmente, justificada por el Tribunal, ya que no advierte contravención del Reglamento del Congreso por parte de la Mesa, que «no ha de motivar o justificar su decisión, [sino que ha sido adoptada] en función de la solicitud elevada por los sujetos legitimados para ejercerla (art. 93.1 RCD)». Estima el Tribunal que la urgencia vendría determinada por el anuncio del término de la legislatura mediante el recurso a la convocatoria de elecciones anticipadas. De ahí que concurrieran «razones de excepcionalidad, por mucho que los recurrentes puedan políticamente no compartidas, que habilitaban a la Mesa para reducir el plazo de presentación de enmiendas previsto en el arto 94 RCD [...] a su mitad». Si bien, dicha declaración de urgencia «no ha impedido a los recurrentes las facultades que les corresponden como Diputados en el seno del procedimiento legislativo», como prueba el que hayan presentado una extensa enmienda a la totalidad.

Todas estas consideraciones le llevan al Pleno del Tribunal a inadmitir el recurso de amparo. Repárese que el Pleno abocó para sí el conocimiento de la demanda de amparo planteada por los recurrentes basado en la vulneración de su derecho fundamental al uis in officium consagrado en el artículo 23.2 de la Constitución; manifestando así la relevancia del tema. Ahora bien, la resolución ha revestido la forma de Auto y no de Sentencia; seguramente, en esta decisión del Tribunal ha pesado la naturaleza del asunto y la gravedad de la crisis económica, que exigía una rápida respuesta por parte del Alto Órgano. La disconformidad con este proceder del Pleno del Tribunal la ha manifestado, mediante la formulación de Voto Particular, el Magistrado Perez Tremps, entendiendo que «debería haberse hecho mediante sentencia y no de forma liminar» ${ }^{62}$; voto al que se adhiere el Magistrado Ortega Alvarez ${ }^{63}$.

Ciertamente, como hemos podido apreciar, ni los Reglamentos parlamentarios ni la Constitución regulan especialidades procedimentales para la revisión constitucional vía artículo $167 \mathrm{CE}$ que excluyan su tramitación por los procedimientos de lectura única ni de urgencia; por ello no puede entenderse que la tramitación procedimental de la reforma del artículo 135 de la Constitución sea inconstitucional. En este sentido, la doctrina constitucional ha reiterado en diversas ocasiones que la inobservancia de los preceptos que regulan el procedimiento legislativo podría acarrear vicios de inconstitucionalidad cuando esa inobservancia altere de modo sustancial el proceso de formación de voluntad en el seno de las Cámaras ${ }^{64}$; aunque no cualquier infracción de los Reglamentos de las Cámaras comporta la declaración inconstitucionalidad, pues lo relevante es determinar las consecuencias que la inobservancia del procedimiento haya podido tener sobre el proceso de formación de la voluntad en el seno de las Cámaras ${ }^{65}$.

62 Además de razones de índole procesal, alega que «Una cuestión técnicamente compleja, novedosa, de evidente interés constitucional, suscitada por parlamentarios representantes del pueblo español no debería haberse inadmitido a trámite sino que debería haber sido objeto de un pronunciamiento más reposado y tras un análisis procesalmente completo de las cuestiones planteadas. Al no haberlo hecho así creo que flaco favor se ha hecho a la interpretación constitucional, a la propia legitimidad institucional del Tribunal Constitucional y a la legitimidad misma de la reforma constitucional llevada a cabo».

63 Considerando, además, que la reflexión sobre la necesidad de establecer la diferente condición de las Cortes Generales cuando actúan como órgano constituido y cuando lo hacen como órgano constituyente», debía haber formado parte del cuerpo de la decisión sobre este asunto.

64 Entre otras vid. SSTC 99/1987, de 11 de junio; 136/2011, de 13 de septiembre.

65 STC 97/2002, de 25 de abril. Vid. sobre este tema BIGLINO CAMPOS, P.: Los vicios en el procedimiento legislativo, CEC, Madrid, 1991. 
La desregulación del procedimiento ordinario de reforma que lleva a cabo la Constitución en su artículo 167 hace difícil que pueda prosperar una declaración de inconstitucionalidad sobre la reforma del artículo 135 operada conforme a este procedimiento; a la vez que permite la utilización de las diversas especialidades en el procedimiento legislativo ordinario para llevar a cabo la citada reforma constitucional, entre las que el Reglamento del Congreso contempla la lectura única o el procedimiento de urgencia, que si que presentan una determinada regulación, por más que lo haga en términos flexibles, de los supuestos en los que procede su utilización en dicho procedimiento.

Concretamente, en el presente caso, en el que la reforma del artículo 135 se aprueba por el procedimiento de lectura única y de urgencia, el Reglamento del Congreso contempla su utilización en los supuestos en los que la naturaleza lo aconseje, la simplicidad lo permita y la urgencia lo exija.

Descartando que un proceso de reforma constitucional pueda entenderse incluido entre las materias cuya naturaleza aconseje el procedimiento de lectura única ${ }^{66}$, debemos centrarnos en el análisis de la existencia del consenso y de su urgencia. En este sentido, la reforma constitucional llevada a cabo aparece avalada por el consenso entre las dos fuerzas políticas mayoritarias. Sin embargo, ese amplio consenso es cuestionable por dos razones: primera, porque se ha orillado la posición de las minorías, cuya participación en el procedimiento ha sido reducida a la mínima expresión ${ }^{67}$. En este sentido, hay que partir del presupuesto de que en las democracias pluralistas la realización efectiva del predominio legítimo de la mayoría debe asegurarse sin que por ello se excluya del sistema a las minorías, pues también ellas conforman el poder público ${ }^{68}$; y es que, no debe confundirse la legitimidad de las decisiones mayoritarias con el entorpecimiento de actuaciones también legítimas de las minorías; pues como tan acertadamente expusiera Zagrebelsky «el peso del número puede y debe valer en el momento del voto, pero antes de ello debería valer el peso de los argumentos» ${ }^{69}$; segunda, porque el consenso alcanzado, de gran

66 En el Voto particular que formula don Eugeni Gay Montalvo al Auto dictado en el R.A. avocado al Pleno núm. 5241-2011, mantiene que, aun coincidiendo con la mayoría en el fallo, lo que no comparte es el argumento de que la concurrencia en este caso de los supuestos previstos en el artículo 150 RCD para aprobarla lectura única se base en que así lo haya considerado el Pleno de la Cámara mediante la oportuna votación.

67 En esta dirección E. ALBERTÍ ROVIRA ha manifestado que da la impresión de que no se «han hecho esfuerzos por conseguir la mayoría» similar a la de 1978. Las consecuencias de ello las advierte pro futuro cuando afirma que sería catastrófico que se acabara imponiendo la idea de que la Constitución en España «a partir de ahora, es cosa sólo de dos», en «la Reforma del Articulo 135 CE», REDC, núm. 93/2011, pág. 167. Igualmente F. BASTIDA considera con el procedimiento seguido rompe con la liturgia democrática requerida por la soberanía popular en un proceso constituyente o de revisión constitucional, pág. 175. Y F. RUBIO LLORENTE apunta que ha sido «Una reforma inopinada, presentada sin estudios previos conocidos, sin discusión pública y tramitada para colmo por el procedimiento de urgencia», pág. 203.

68 En este sentido, L. AGUIAR DE LUQUE, afirmaba que »el Derecho Parlamentario, hoy, en los Estados democráticos, parlamentarios y pluralistas, está presidido por una tensión distinta, la tensión dialéctica mayoría-minoría y su principio rector, ya no puede seguir siendo la garantía de unos ámbitos exentos de injerencias de la Corona, sino la realización del valor superior del pluralismo (art. 1.1 de la CE), garantizando los derechos de las minorías y la publicidad de los debates», en «El Tribunal Constitucional y la función legislativa: el control del procedimiento legislativo y de la inconstitucionalidad por omisión», Revista de Derecho Político, núm. 24/1987, pág. 18.

69 ZAGREBELSKY, G ., »Ostruzionismo parlamentare dell'opposizione e della maggioranza. Uso degli articoli 30,44, 65 e 92 del Regolamento», en Il Parlamento nella Costituzione e nella Realta, Giuffre, Milano, 1979, pág. 395. 
amplitud cuantitativa, al converger en él los dos grupos políticos mayoritarios, es cualitativamente cuestionable, al postergar a grupos políticos minoritarios, pero de gran trascendencia política enraizados en el consenso constitucional, que queda cuestionado por esta reforma constitucional.

Por su parte, la alegada urgencia, igualmente, debe descartarse de raíz, y ello por varias razones: en primer lugar, por la existencia de un ordenamiento jurídico, tanto nacional como comunitario, que propugna entre sus principios presupuestarios el de estabilidad, avalado por el Tribunal Constitucional, que ha defendido el acomodo constitucional del establecimiento de límites en la elaboración de los Presupuestos de las Comunidades Autónomas y de las Corporaciones Locales. En segundo lugar, porque el mandato político de reforma constitucional auspiciado por el eje franco-alemán tenía como término diciembre de 2012. Y en último lugar, y fundamentalmente, porque la propia reforma constitucional fija la entrada en vigor de los límites de déficit estructural permitido a las Administraciones Públicas para el año 2020 (Disposición adicional única, ap. 3). Razones todas, que han llevado, incluso, a cuestionar la necesidad de la refor$\mathrm{ma}^{70}$; sobre todo si tenemos en cuenta que «la reforma es siempre políticamente conveniente cuando resulta jurídicamente necesaria» ${ }^{71}$. Apreciaciones que se ven confirmadas con el reciente acuerdo de adopción de un Tratado Internacional entre los países integrantes de la zona euro junto con el resto de los Estados miembros de la Unión Europea —a excepción del Reino Unido y la República Checa_, en fecha 30 de enero de 2012, a falta de ratificación, en el que se propugna la necesaria integración del principio de estabilidad presupuestaria, en los términos de exigencia a los Estados de un déficit máximo del $0,5 \%$ del producto interior bruto, en los textos constitucionales de los Estados firmantes; previéndose, en su caso, su entrada en vigor en fecha 1 de enero de 2013. Tarea a la que España se ha adelantado.

A la luz de lo cual, descartando la alegada inconstitucionalidad del procedimiento de reforma, no parece que las exclusivas exigencias del interés de los mercados puedan justificar una reforma de la Constitución que sacrifique el consenso constitucional.

70 En este sentido, J. MARTÍN QUERALT defiende «que no es estrictamente necesario acudir al expediente de modificación constitucional que se ha planteado», cit. pág. 7. En el mismo sentido, G. CÁMARA ha manifestado que «lo procedente hubiera sido reafirmarlo [el principio de estabilidad presupuestaria] en el plano legal y emprender las modificaciones que fueran necesarias, buscando el mismo efecto de ofrecimiento de garantías a los mercados financieros, tanto por la propia operatividad de la normativa y la acción de los poderes públicos, cuanto por la difusión ante las agencias de valoración y el conjunto de los agentes económicos a través de los medios de comunicación», en «la Reforma del Articulo 135 CE», REDC, núm. 93/2011, pág.180. Del mismo modo, J.L. CASCAJO CASTRO se pregunta «si la reforma constitucional no ha resultado desproporcionada y si una ley orgánica orientada a cubrir los mimos objetivos hubiera sido suficiente», pág. 194. Por su parte, F. DE CARRERAS la ha calificado de «inútil, vacía y mal tramitada», La Vanguardia, 1/09/2011.

71 P. DE VEGA: La Reforma Constitucional y la problemática del poder constituyente, Tecnos, Madrid, 2007, pág. 92. 
TTITLE: The Reform of Article 135 of the Spanish 1978 Constitution: Can Markets Break the Constitutional Consensus?

ABSTRACT: This work analyzes the reform of article 135 of the Spanish Constitution which was introduced in September 2011, from the perspective of the constitutional principles as well as the decisions taken by the Constitutional Court. The focus is mainly on the analysis of the procedure followed to conduct the reform, which-it was said-severely breaks the constitutional consensus.

RESUMEN: Este trabajo analiza la reciente reforma del artículo 135 de la Constitución española, a la luz de los principios y de la doctrina constitucional; centrándose, fundamentalmente, en el estudio crítico del procedimiento de reforma seguido, que cuestiona el consenso constitucional.

KEYWORDS: Constitutional reform. Reform process. Guarantees of parliamentary procedure. Budgetary stability. European Union. Constitutional consensos. Rights of minorities

Palabras Clave: Reforma constitucional. Procedimiento de reforma. Garantías del procedimiento parlamentario. Estabilidad presupuestaria. Unión Europea. Derechos de las minorías. Consenso constitucional

FECHA RECEPCIÓN: 01.02.2012 FECHA ACEPTACIÓN: 15.02.2012 